\title{
Strain-dependent release of cytokines modulated by Lactobacillus salivarius human isolates in an in vitro model
}

\author{
Lorenzo Drago ${ }^{1,2^{*}+}$, Lucia Nicola $^{1,2+}$, Enrico lemoli ${ }^{3 \dagger}$, Giuseppe Banfi ${ }^{4}$, Elena De Vecchi ${ }^{1,2+}$
}

\begin{abstract}
Background: Oral administration of probiotics is known to modulate cytokines profile not only locally, but also systemically. Four strains of Lactobacillus salivarius, LDR0723, BNL1059, RGS1746 and CRL1528, were evaluated for their ability to modulate release of pro- and anti-inflammatory cytokines.

Findings: Strains were assessed for effects on production of Interleukin-12 (IL-12), Interferon- $\gamma$ (IFN- $\gamma$ ), Interleukin-4 (IL-4) and Interleukin-5 (IL-5) by incubating bacterial suspensions with THP-1 macrophage like cells. Cytokines were determined by means of specific quantitative enzyme-linked immunosorbent assays.

LDR0723 and CRL1528 led to a sustained increment in production of IL-12 and IFN- $\gamma$ and to a decrease in release of IL-4 and IL-5, while BNL1059 and RGS1746 favoured Th2 response, leading to a decrease in Th1/Th2 ratio with respect to unstimulated cells.
\end{abstract}

Conclusions: In conclusion, capability of L. salivarius to modulate immune response was strictly strain dependent and strains of the same species might have opposite effects. Therefore, a careful evaluation of anti-inflammatory properties of lactobacilli should be performed on single strain, before any consideration on potential probiotic use.

\section{Findings}

Oral administration of lactobacilli may modulate cytokines profile not only at intestinal level but also systemically [1]. The main difference between the mucosal and systemic immunities is that in the former the mechanisms of innate immunity and the activation of B cells for mucosal immunity are more important than the adaptive immune response involving the $\mathrm{T}$ cell population.

At the gut mucosal level, the innate immune response provides the first line of defence against pathogenic microorganisms which is initiated by immunoglobulin A (IgA) secretion. Studies with animal models have shown that intestinal microorganisms increase the numbers of IgA-secreting plasma cells, thus up-regulating IgA secretion, although the precise mechanisms underlying the way these bacteria modulate the intestinal immune system still remain unclear. Interactions among antigenpresenting cells (APCs) naïve T cells and B cells lead to

\footnotetext{
* Correspondence: lorenzo.drago@unimi.it

† Contributed equally

${ }^{1}$ Laboratory of Microbiology, Department of Preclinical Sciences LITA Vialba, University of Milan, Milan, Italy
}

generation of B cells with a high level of IgA expression. Ag-activated $\mathrm{T}$ and $\mathrm{B}$ cells may migrate from the inductive environment to effector sites through lymphatic drainage and blood-stream. Multiple cytokines, including TGF- $\beta$ and IL-4, IL-5, IL- 6 and IL-10 are required to promote IgA class switching and maturation [2].

Cytokines produced by immunocompetent cells such as APCs and T lymphocytes have been advocated to play a significant role in several diseases, such as inflammatory bowel disease (IBD), irritable bowel syndrome (IBS) and allergies. Crohn's disease and ulcerative colitis, the major forms of IBD in humans are associated with exaggerated and poorly controlled Th1 or Th2 responses, respectively, and with a more complex networks of cytokine interactions, involving Th17 [3].

Lactobacilli have been shown to activate monocytes and macrophages, which play a pivotal role in antigen processing, presentation and activation of antigen-specific immunity and to stimulate IgA immunity. In particular, these cells together with dendritic and $\mathrm{T}$ regulatory cells are essential in the deviation of immune response to the so called type 1 response with cytotoxic effector 
cells or towards type 2 response characterized by antibody response. Type 2 response is related to secretion of IL-4, IL-5, IL-9 and IL-13 which promote induction of IgE and allergic response.

Effects of lactobacilli on host immune systems are known to depend on the bacterial species involved, since different strains are able to stimulate release of different cytokines. Results pointing toward stimulation of both Th1 and Th2 responses have been observed in animals fed with probiotics while few or no data are available on strains of human origin [4].

Aim of this study was to in vitro evaluate the release of pro- and anti-inflammatory cytokines induced by four strains of Lactobacillus salivarius of human origin.

\section{Bacterial strains and cell cultures}

Lactobacillus salivarius strains LDR0723, BNL1059, RGS1746 and CRL1528 were isolated from vaginal brushing or faeces of four different apparently healthy subjects, who declare to have not consumed probiotic containing products in the two weeks preceeding sample collection. Samples were plated on homofermentativeheterofermentative differential (HHD) agar and incubated for 48-72 $\mathrm{h}$ in anaerobiosis.

Lactobacilli strains were initially identified by means of a biochemical assay based on carbohydrate fermentation (API50 CHL, BioMerieux Marcy L'Etoile, France). Identification of L. salivarius strains was further confirmed by PCR, as described by Chaugnaud et al [5].

Lactobacilli were stored at $-80^{\circ} \mathrm{C}$ in MRS broth supplemented with $10 \%$ of glycerol until use.

Before experiments, bacteria were thawed and grown on MRS agar plates at $37^{\circ} \mathrm{C}$ in $10 \% \mathrm{CO}_{2}$ enriched atmosphere for $24 \mathrm{~h}$ for two times and then subcultured in MRS broth for $24 \mathrm{~h}$ at $37^{\circ} \mathrm{C}$ in $10 \% \mathrm{CO}_{2}$ enriched atmosphere.

The human macrophage-like cell line THP-1 (Istituto Zooprofilattico Brescia, Italy) was grown in culture flasks in RPMI-1640 medium (Sigma - Aldrich, Milan, Italy) enriched with $10 \%$ heat-inactivated foetal bovine serum (Sigma-Aldrich), $0.05 \mathrm{mM} \beta$-mercaptoethanol (Sigma-Aldrich), 1\% Na-pyruvate (Sigma-Aldrich), 1\% glutamine (Sigma-Aldrich) and $1 \%$ penicillin/streptomycin (Sigma-Aldrich). Cells were incubated at $37^{\circ} \mathrm{C}$ in a humified atmosphere containing $5 \% \mathrm{CO}_{2}$.

\section{Stimulation of THP-1 cells with lactobacilli}

Overnight bacterial cultures were washed twice with phosphate buffered saline buffer (PBS), pH 7.2, before being resuspended at a concentration of about $2 \times 10^{9}$ $\mathrm{CFU} / \mathrm{ml}$

Ten microliters of each bacterial suspension were transferred into the wells of a 24-wells plate containing $2 \times 10^{6} \mathrm{THP}-1$ cells $/ \mathrm{mL}$, and incubated at $37^{\circ} \mathrm{C}$ in a $5 \%$
$\mathrm{CO}_{2} / 95 \%$ air atmosphere. After $24 \mathrm{~h}$ incubation, the supernatant was aspirated, centrifuged at $2000 \mathrm{rpm}$ and stored at $-20^{\circ} \mathrm{C}$. Cells receiving PBS only were used as unstimulated control. Each test was performed in triplicate. Vitality of L. salivarius strains, evaluated by means of growth curves, was not affected by incubation in RPMI-1640 medium. No notable changes in THP-1 cells counts were observed after incubation with L. salivarius with respect cells receiving only PBS.

Production of IL-12, IFN- $\gamma$, IL-4 and IL-5 was determined by means of specific quantitative enzyme-linked immunosorbent assays (ELISA) (BenderMedSystems, Wien, A), according to the manufacturer's instructions. Absorbance was measured at $450 \mathrm{~nm}$ using a Biorad spectrophotometer (mod 680 Biorad, Segrate, Italy). For each cytokine a standard curve was constructed in duplicate and used to quantify amount of cytokine (pg) per $\mathrm{mL}$ of culture medium. Ratio between Th1 and Th2 response was calculated as ratio between concentrations of Th1 cytokines (IL-12 + IFN- $\gamma$ ) and Th2 interleukins (IL-4 + IL-5).

Results were reported as differences (\%) vs unstimulated cells of three different experiments in triplicate. Statistical differences were evaluated with one way ANOVA followed by Tuckey $\mathrm{T}$ test. Differences were considered as statistically significant when P-value was equal or less than 0.05 .

The four strains of $L$. salivarius showed a different ability to modulate production of IFN- $\gamma$ and IL-12 in THP-1 monocyte cells (Figure 1). Production of IFN- $\gamma$ was greatly stimulated by strains LDR0723 and CRL1528, while only slight increments were observed in cells treated with BNL1059 and RGS1746. Significant differences in IFN- $\gamma$ production were observed between LDR0723 and BNL1059 and RGS1746 and between CRL1528 and BNL1059 and RGS1746. All the four strains stimulate production of IL-12, although at

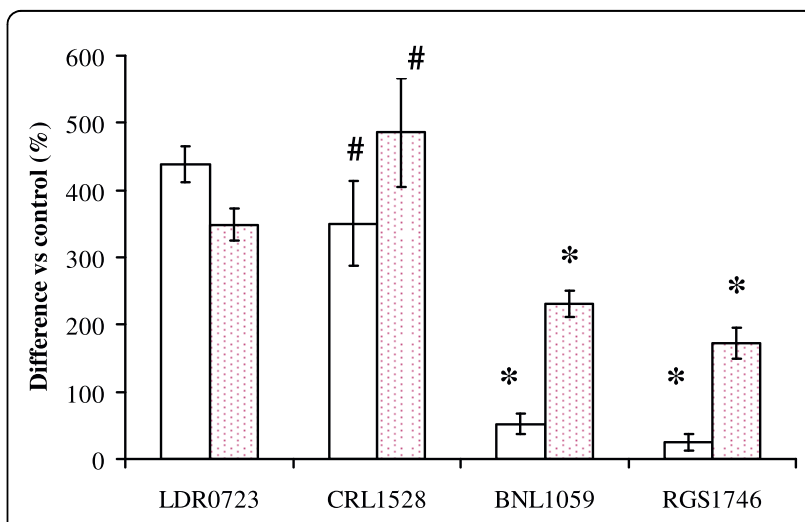

Figure 1 Release of Th1 cytokines by THP-1 cells. Open bars: IFN- $\gamma$, Pointed bars: IL-12. Data are means of three experiments \pm $S D * p<0.05$ vs LDR0723 and CRL1528; \#: $p<0.05$ vs LDR0723. 
different rate, with LDR0723 and CRL1528 inducing significantly higher levels than BNL1059 and RGS1746.

With respect to unstimulated cells, BNL1059 and RGS1746 led to an increment in production of IL-4 in THP-1 cells, while diminished levels of IL-4 were observed in LDR0723 and CRL1528 treated cells (Figure 2). Production of IL- 5 was stimulated by all the four strains, with significant higher levels observed in BNL1059 and RGS1746 treated cells with respect to LDR0723 and CRL1528 strains (Figure 2).

Th1/Th2 ratios are shown in Figure 3. L. salivarius strains LDR0723 and CRL1528 significantly moved Th1/ Th2 balance toward Th1 response, while BNL1059 and RGS1746 led to a decrease of the Th1/Th2 ratio in favour of pro-inflammatory cytokines.

\section{Conclusions}

Inflammation and immunity changes are generally critical for the development of nearly every complex

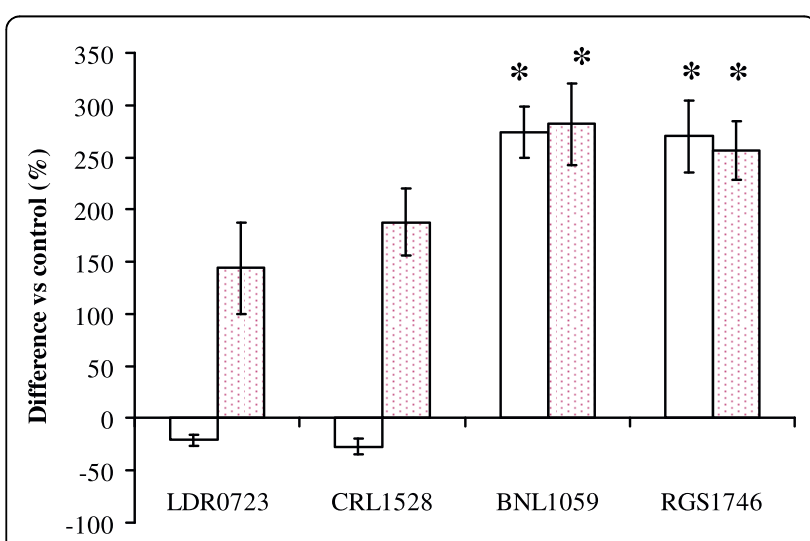

Figure 2 Release of Th2 cytokines by THP-1 cells. Open bars:IL-4, Pointed bars: IL-5. * $p<0.05$ vs control (unstimulated cells). Data are means of three experiments \pm SD * $p<0.05$ vs LDR0723 and CRL1528.

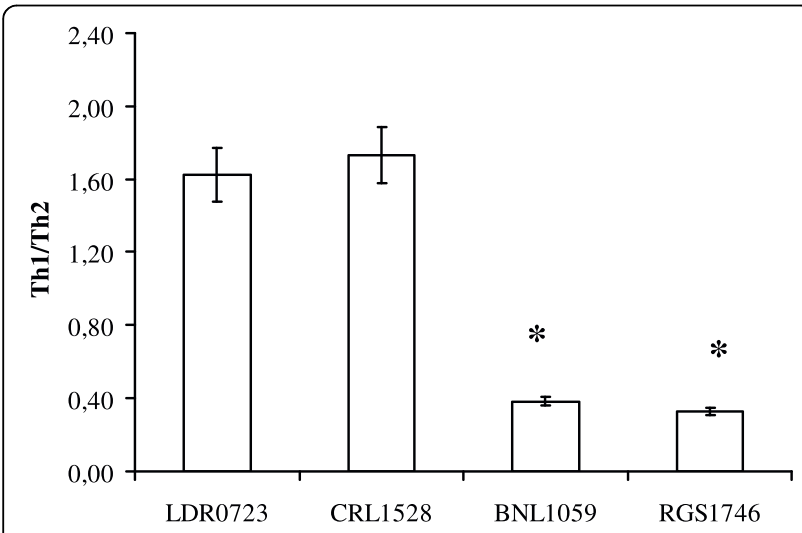

Figure 3 Ratio between Th1 and Th2 responses. Data are means of three experiments \pm SD ${ }^{*} p<0.05$ vs LDR0723 and CRL1528. condition. Alterations in equilibrium between Th-1 and Th-2 responses have been linked to the pathogenesis of a wide variety of diseases such as IBD, IBS and allergies. Different patterns of cytokines are involved in the pathogenesis of these diseases and they may act in opposite ways, as observed, for instance in IBD, where Crohn's disease lesion is related to a predominant activation of Th1-lymphocytes, while lesion of ulcerative colitis is mainly driven by Th2 cytokines [6,7]. Knowledge on the immune-mediated mechanisms in metabolic scenario has markedly increased in the recent past, evidencing the role that dietary components may have to modulate immunity by enhancing or suppressing the immune response. For instance, certain strains of probiotics have been demonstrated to be able to modulate the immune system by stimulating release of different patterns of cytokines by different cells [8].

In this study, four strains of L. salivarius of human origin were evaluated for their capabilities to influence production of pro- and anti-inflammatory cytokines by THP-1 cells. These cells were preferred to peripheral blood monocytes (PBMC) since the use of a cell line allowed us to standardize the assay, avoiding variability due to the fact that PBMCs harvested by apparently healthy subjects, may be influenced in their response by intrinsic factors due to individual variability.

Our results showed that the observed effects on cytokines' release are strictly strain-specific, since strains of the same species may modulate different patterns of cytokines and thus they may have opposite effects in the same condition. In fact, of the four strains of $L$. salivarius tested in the study, two modulated cellular immunity towards Th1, while the rest favoured a Th2 response. In comparison to unstimulated cells, LDR0723 and CRL1528 strains seemed to differ in their activity. In fact, LDR0723 favoured production of IL-12 rather than of IFN- $\gamma$, while a more sustained increment in release of IFN $-\gamma$ than of IL-12 was produced by CRL1528. An increment in production of IL-12 levels was found also in cells stimulated with BNL1059 and RGS1746, even though they mainly oriented Th1/Th2 balance vs Th2. IL-12 has an essential role in Th1 development, stimulating activated $\mathrm{T}$ cells and NK cells to maximally produce IFN- $\gamma$, and inhibiting IL-4 induced IgE production by human PBMC in vitro [9]. In turn, IFN- $\gamma$ promotes differentiation of naive Th lymphocytes (Th-0) towards a Th-1 subsets, prevents proliferation of Th2 lymphocytes and acts on B cells to inhibit switching to IgE [10]. By contrast, BNL1059 and RGS1746 favoured production of IL-4 which is known to promote production of IgE [10] and, at a lesser extent, of IL-5 which specifically controls production and activation and localization of eosinophils, the major cause of tissue damage in atopic disease [11]. Eosinophils have been recently shown to 
constitutively store cytokine associated with Th1, Th2 and $\mathrm{T}$ regulatory responses, although a preferential Th2 cytokine secretion occurs in response to immuno-polarizing cytokine signal [12]. Lack of IL-4 has been recently reported to modulate gut mucosal response in food allergy through diminished expression of TNF- $\alpha$ mRNA, increased Th1 IFN- $\gamma$, IL-12p40 regulatory cytokines, thus demonstrating their relevance in the control of allergic inflammatory processes, especially in the intestine [13]. Moreover, IL-12, IFN- $\gamma$ and IL-4 inhibit Th17 differentiation for human cells, which is the main responsible rather than Th1 subsets for inflammation in autoimmunity disorders $[14,15]$. IL-4 and IL-5 are required to promote maturation of IgA, which appears, in terms of humoral immunity at mucosal surfaces, to combine properties of a neutralizing agent and of a mucosal immunopotentiator inducing effector immune response in a noninflammatory context favourable to preserve local homeostasis of the gastrointestinal tract [2].

The mechanism involved in the different immuno-stimulatory ability of different strains of lactobacilli belonging to the same species has not yet been fully elucidated and its evaluation was beyond the aim of this study. The differential immunostimulating property of LTAs from bacteria with different pathogenicity seems to correlate with content of D-alanine residues in the repetitious chains of the LTA. In addition, a mutant of Lactobacillus plantarum defective in D-alanylation of LTA has been shown to reduce the release of inflammatory cytokines from PBMC $[16,17]$. Therefore, composition in LTA might influence release of inflammatory cytokines $[16,17]$ as well as it has been shown that the strain-dependent ability to promote synthesis of IL-12 may arise, at least in part, from the amount of peptidoglycan present in gram-positive bacteria, and that integrity of bacterial cell wall is essential for the induction of IL-12 production $[18,19]$. Moreover it may be hypothesized that other cellular components or bacterial products released by each single strain might be involved.

In the present study only four cytokines were assessed. However, they are representative of Th1 or Th2 responses and have been often used to evaluate the effect of lactobacilli and other bacteria on immune system [20-22].

In conclusion data obtained in this study evidenced that strains of the same species of Lactobacillus exhibited different modulation of immune response towards Th1 or Th2. For this reason, assessment of candidate probiotic strains for their immunomodulatory properties seems to be of notable importance to assure safety of their use and efficacy in treatment of immune-mediated diseases.

\section{Author details}

'Laboratory of Microbiology, Department of Preclinical Sciences LITA Vialba, University of Milan, Milan, Italy. ${ }^{2}$ Laboratory of Clinical Chemistry and Microbiology, IRCCS Galeazzi Institute, Via R. Galeazzi 4, 20161 Milan, Italy. ${ }^{3}$ Allergology Unit, L. Sacco Teaching Hospital, Milan, Italy. ${ }^{4}$ Scientific Direction, IRCCS Galeazzi Institute, Department of Health Technologies, University of Milan, Milan, Italy.

\section{Authors' contributions}

LD participated in designing the study, data analysis and in the writing of the paper. LN performed all experiments and participated in data collection and analysis. El participated in writing of the paper. EDV participated in designing the study, data analysis and in the writing of the paper. GB contributed to preparation of the manuscript. All authors read and approved the final manuscript.

\section{Competing interests}

The authors declare that they have no competing interests.

Received: 17 November 2009 Accepted: 25 February 2010 Published: 25 February 2010

\section{References}

1. Solis-Pereyrs B, Aattouri N, Lemonnier D: Role of food in the stimulation of cytokine production. Am J Clin Nutr 1997, 66:521S-522S.

2. Corthesy B: Roundtrip ticket for secretory IgA: role in mucosal homeostasis. J Immunol 2007, 178:27-32.

3. McGovern D, Powrie F: The IL23 axis plays a key role in the pathogenesis of IBD. Gut 2007, 56:1333-1336.

4. Cross ML: Microbes versus microbes: immune signals generated by probiotic lactobacilli and their role in protection against microbial pathogens. FEMS Immunol Med Microbiol 2002, 34:245-253.

5. Chagnaud P, Machinis K, Coutte AL, Marecat A, Mercenier A: Rapid PCRbased procedure to identify lactic acid bacteria: application to six common Lactobacillus species. J Microbiol Met 2001, 44:139-148.

6. Neurath MF, Weigmann B, Finotto $S$ : The transcription factor T-bet regulates mucosal T cell activation in experimental colitis and Crohn's disease. J Exp Med 2002, 195:1129-1143.

7. Heller F, Florian P, Bojarski C, Richter J, Christ M, Hillenbrand B, Mankertz J, Gitter AH, Burg Fuss I, Strober W, Schulzke JD: Interleukin-13 is the key effector Th2 cytokine in ulcerative colitis that affects epithelial tight junctions, apoptosis, and cell restitution. Gastroenterology 2005, 129:550-564.

8. Ongol MP, Iguchi T, Tanaka M, Sone T, Ikeda H, Asano K, Nishimura T: Potential of selected strains of lactic acid bacteria to induce a Th1 immune profile. Biosci Biotechnol Biochem 2008, 72:2847-2857.

9. Manetti R, Parronchi P, Giudizi MG, Piccinni P, Maggi E, Trinchieri G, Romagnani S: Natural killer cell stimulatory factor (interleukin 12 [IL-12]) induces T-helper type (Th1)-specific immune responses and inhibits the development of IL-4 producing Th cells. J Exp Med 1993, 177:1199-1204.

10. Pène J, Rousset F, Brière F, Chretien I, Bonnefoy JY, Spits H, Yokota T, Arai N, Arai $\mathrm{K}$, Banchereau J: IgE production by normal human lymphocytes is induced by interleukin 4 and suppressed by interferons gamma and alpha and prostaglandin E2. Proc Natl Acad Sci USA 1988, 85:6880-6884.

11. Mordvinov VA, Sanderson CJ: Regulation of IL-5 expression. Arch Immunol Ther Exp 2001, 49:345-351.

12. Spencer LA, Szela CT, Perez SAC, Kirchhoffer CL, Neves JS, Radke AL, Weller PF: Human eosinophils constitutively express multiple Th1, Th2, and immunoregulatory cytokines that are secreted rapidly and differentially. J Leukoc Biol 2009, 85:117-123.

13. Cardoso CR, Provinciatto PR, Godoi DF, Ferreira BR, Teixeira G, Rossi MA, Cunha FQ, Silva JS: IL-4 regulates susceptibility to intestinal inflammation in murine food allergy. Am J Physiol Gastrointest Liver Physiol 2009, 296: G593-600.

14. Wilson NJ, Boniface $K$, Chan JR, McKenzie BS, Blumenschein WM, Mattson JD, Basham B, Smith K, Chen T, Morel F, Lecron JC, Kastelein RA, Cua DJ, McClanahan TK, Bowman EP, de Waal Malefyt R: Development, cytokine profile and function of human interleukin 17-producing helper T cells. Nat Immunol 2007, 8:950-957. 
15. Goriely S, Cavoy R, Goldman M: Interleukin-12 family members and type I interferons in Th-17-mediated inflammatory disorders. Allergy 2009, 64:702-709.

16. Grangette C, Nutten S, Palumbo E, Morath S, Hermann C, Dewulf J, Pot B, Hartung T, Hols P, Mercenier A: Enhanced antiinflammatory capacity of a Lactobacillus plantarum mutant synthesizing modified teichoic acids. Proc Natl Acad Sci USA 2005, 102:10321-10326.

17. Ryu YH, Baik JE, Yang JS, Kang SS, Im J, Yun CH, Kim DW, Lee K, Chung DK, Ju HR, Han SH: Differential immunostimulatory effects of Gram-positive bacteria due to their lipotheicoic acids. Int Immunopharmacol 2009, 9:127-133.

18. Sashihara T, Sueki N, Ikegami S: An analysis of the effectiveness of heatkilled lactic acid bacteria in alleviating allergic diseases. J Dairy Sci 2006, 89:2846-2855

19. Shida K, Kiyoshima-Shibata J, Nagaoka K, Watanabe K, Nanno M: Induction of interleukin-12 by Lactobacillus strains having a rigid cell wall resistant to intracellular digestion. J Dairy Sci 2006, 89:3306-3317.

20. Hougee S, Vriesema AJ, Wijering SC, Knippels LM, Folkerts G, Nijkamp FP, Knol J, Garssen J: Oral treatment with probiotics reduces allergic symptoms in ovalbumin-sensitized mice: a bacterial strain comparative study. Clin Exp Immunol 2007, 149:344-352.

21. Miettinen $\mathrm{M}$, Matikainen S, Vuopio-Varkila J, Pirhonen J, Varkila K, Kurimoto $\mathrm{M}$, Julkunen I: Lactobacilli and streptococci induce interleukin12 (IL-12), IL-18, and gamma interferon production in human peripheral blood mononuclear cells. Infect Immun 1998, 66:6058-6062.

22. Foligne B, Nutten $S$, Grangette $C$, Dennin V, Goudercourt D, Poiret $S$, Dewulf J, Brassart D, Mercenier A, Pot B: Correlation between in vitro and in vivo immunomodulatory properties of lactic acid bacteria. World $J$ Gastroenterol 2007, 13:236-243.

doi:10.1186/1756-0500-3-44

Cite this article as: Drago et al: Strain-dependent release of cytokines modulated by Lactobacillus salivarius human isolates in an in vitro model. BMC Research Notes 2010 3:44.

\section{Submit your next manuscript to BioMed Central and take full advantage of:}

- Convenient online submission

- Thorough peer review

- No space constraints or color figure charges

- Immediate publication on acceptance

- Inclusion in PubMed, CAS, Scopus and Google Scholar

- Research which is freely available for redistribution

Submit your manuscript at www.biomedcentral.com/submit
Biomed Central 